\title{
Delayed matching-to-sample trained with retractable levers is impaired by lesions of the intralaminar or ventromedial but not the laterodorsal thalamic nuclei
}

\author{
JOSHUA A. BURK and ROBERT G. MAIR \\ University of New Hampshire, Durham, New Hampshire
}

\begin{abstract}
Rats were trained to perform a delayed matching-to-sample (DMS) task with retractable levers and were then given one of four treatments: control surgery or lesions of the intralaminar (ILn), ventromedial (VMn), or laterodorsal (LDn) thalamic nuclei. The ILn and VMn lesions affected response accuracy in a delay-independent fashion and were associated with slower response times for both the sample and the choice responses of the DMS task. The LDn lesion had little effect on this task. The effects of ILn and VMn lesions on DMS speed and accuracy are consistent with the findings of other studies on the effects of lesioning this area of thalamus and with impairments observed for human Korsakoff syndrome patients. It is argued that the effects of ILn and VMn lesions on DMS may be related to the function of these nuclei in the recurrent feedback pathways that connect functionally related areas of the basal ganglia and frontal cortex.
\end{abstract}

It is well established that diseases affecting midline areas of thalamus can produce severe and persistent signs of amnesia (Graff-Radford, Tranel, van Hoesen, \& Brandt, 1990; Markowitsch, 1991; Victor, Adams, \& Collins, 1989; von Cramon, Hebel, \& Schuri, 1985). Disagreement remains, however, about which pathways or nuclei in this area of the brain are critical for remembering. Two systems have dominated this debate: the mediodorsal nucleus and its projections to prefrontal cortex (Markowitsch, 1982; Victor et al., 1989) and hippocampal-related pathways associated with the anterior or the laterodorsal thalamic nuclei (LDn; see Aggleton \& Sahgal, 1993; Brion \& Mikol, 1978; Parkin, Rees, Hunkin, \& Rose, 1994). Other evidence has pointed to a third possibility: that amnesia may result from damage to the intralaminar nuclei (ILn) or other nonspecific nuclei associated with the internal medullary lamina or midline areas of thalamus (Mair, 1994; W. P. G. Mair, Warrington, \& Weiskrantz, 1979; Malamud \& Skillicorn, 1956; Mennemeier, Fennell, Valenstein, \& Heilman, 1992; von Cramon et al., 1985).

Recent studies of animal models have provided several lines of evidence that the rostral group of the ILn is critical for remembering and may represent an important site of pathology in the Wernicke-Korsakoff syndrome,

This research was supported by NINDS Grant NS 26855. A preliminary report of this work appeared in abstract form (Burk, Glode, Porter, Pelletier, \& Mair, 1997). The authors thank Jennifer Koch, Barbara Glode, M. Christine Porter, Jessica Pelletier, Ben Hardy, Meg Toupin, Julie Zawacki, Sara Burton, Jason Krienke, Michelle Phillips, and Melissa Rose for technical assistance. Correspondence should be addressed to R. G. Mair, Psychology Department, University of New Hampshire, Durham. NH 03824 (e-mail: rgm@christa.unh.edu). the most common cause of diencephalic amnesia. First, the ILn have been found to be vulnerable to the effects of thiamin deficiency, the main etiologic factor in the Wernicke-Korsakoff syndrome (Langlais, Zhang, \& Savage, 1996; Mair, 1994; Mair, Anderson, Langlais, \& McEntee, 1988). Second, the extent of internal medullary lamina (or ILn) damage has been found to predict the extent of behavioral impairment in rats that have recovered from experimentally induced thiamin deficiency. Thus, rats with lesions involving extensive areas of the ILn perform poorly on delayed matching-to-sample (DMS) and delayed nonmatching-to-sample (DNMS) tasks used to measure remembering (Knoth \& Mair, 1991; Langlais \& Savage, 1995; Robinson \& Mair, 1992). Third, comparable DNMS and DMS impairments have been observed in multiple sensory modalities after either electrolytic or excitotoxic lesions affecting the ILn (Burk \& Mair, 1998; Mair, 1994; Mair, Burk, \& Porter, 1998; Zhang, Burk, Glode, \& Mair, 1998). Thus, similar signs of memory impairment have been observed in rats with ILn lesions that have no history of thiamin deficiency. Fourth, comparable DNMS or DMS impairments are not observed following lesions of mediodorsal nuclei, fornix, mammillary bodies, or hippocampus (Burk \& Mair, 1998; Mair, 1994; Zhang et al., 1998). Thus, the behavioral impairments associated with ILn lesions do not seem to be related to any unintentional damage to adjacent areas of the mediodorsal nuclei or to pathways that travel from hippocampus through fornix or mammillary bodies to innervate the anterior thalamic nuclei. Fifth, when performances are compared across different tasks, distinct patterns of impairment are observed for rats with lesions of the ILn, hippocampus, or prefrontal cortex (Mair et al., 1998). Thus, 
these lesions seem to have different functional effects on the capacity to remember.

This report addresses two issues related to the behavioral impairments associated with ILn lesions. The first concerns the possible involvement of the LDn or the ventromedial nuclei (VMn), structures that were frequently damaged by lesions aimed at the ILn in previous experiments (Burk \& Mair, 1998; Mair, 1994; Zhang et al., 1998). In the rat, the VMn are the place of convergence for pathways involved in motor control originating in substantia nigra pars reticulata, entopeduncular nucleus, superior colliculus, and cerebellum; and they project diffusely to layer I of cerebral cortex (Faull \& Mehler, 1985; Herkenham, 1979; Jones, 1985). The LDn provide important afferent input to the subicular complex (van Groen \& Wyss, 1992) and have been shown to be critical for the coding of place information by hippocampal neurons and for the ability of rats to perform a DNMS task in the radial arm maze (Mizumori, Miya, \& Ward, 1994; Mizumori \& Williams, 1993). We investigated the involvement of the LDn and VMn by comparing the effects of lesions aimed at these nuclei to lesions of the ILn, designed to produce less collateral damage than in previous studies, on a DMS task that has been shown to be sensitive to the effects of lesioning the ILn (Burk \& Mair, 1998).

The second issue concerns the effects of thalamic lesions on response speed. Previous studies have shown that rats with ILn lesions respond slowly in DMS and DNMS tasks, making choice responses at abnormally long latencies after the end of retention intervals (Burk \& Mair, 1998; Knoth \& Mair, 1991; Mair \& Lacourse, 1992). To better characterize the effects of these lesions on response speed, we subdivided DMS trials more systematically, comparing the latencies for executing the sample response, initiating the choice response (at the end of the retention interval), and executing the choice response. Comparing latencies in this manner provides a test of whether ILn lesions have a specific effect on the speed of the conditional choice response or whether these lesions have a more general effect on other components of the DMS task.

\section{METHOD}

\section{Subjects}

The subjects included 40 male Long-Evans rats (Charles River Breeding Labs, Wilmington, MA) that were individually housed in a temperature- and humidity-controlled vivarium on a 12:12-h light: dark cycle. The rats received ad-lib access to food and were maintained on a water-deprivation schedule so that water could be used as a reinforcer. This was done by limiting the rats to $30 \mathrm{~min}$ free access to water per day in addition to the 7-10 ml consumed during daily training trials. The period of free access was increased to $60 \mathrm{~min}$ on days when the rats did not receive training (with water reinforcement).

\section{Treatment}

The rats were trained to perform the DMS task, matched for percent correct responding over the last three presurgical sessions, and then assigned by a random matching procedure to one of four treatment groups: sham surgery or ILn, VMn, or LDn lesion. There were 10 animals in each group.

The rats were anesthetized with an intramuscular injection of ketamine $(85 \mathrm{mg} / \mathrm{kg})$ and xylazine $(8.5 \mathrm{mg} / \mathrm{kg})$ and then placed in a stereotaxic instrument with the incisor bar set $3.3 \mathrm{~mm}$ below the interaural (IA) line. After the skull was opened with sterile procedures, lesions were made by infusing a $150-\mathrm{mM}$ solution of $N$-methylD-aspartate (NMDA) in phosphate buffer $(\mathrm{pH}=7.4)$ through a 26-ga cannula attached to a $10-\mu 1$ syringe mounted in a Kopf (Tujunga, CA) Model 5000 microinjection unit. Lesions were made at a series of sites by injecting $0.1 \mu \mathrm{l}$ of the NMDA solution over a period of $30 \mathrm{sec}$. The cannula was left in place for $1 \mathrm{~min}$ after each injection. The main differences between the procedures followed for producing the ILn lesion this study compared with previous studies (Burk \& Mair, 1998; Mair et al., 1998; Zhang et al., 1998) was the reduction in injection volume from 0.4 or $0.2 \mu \mathrm{l}$ to $0.1 \mu \mathrm{l}$ and the increase in NMDA concentration from 100 to $150 \mathrm{mM}$. The DV coordinates for the ILn lesion were changed slightly from these previous studies to minimize the ventral extent of damage.

All three lesion groups were given bilateral lesions at 5.2, 6.2, and $7.2 \mathrm{~mm}$ anterior to the IA line. The AP and DV coordinates are given in millimeters relative to IA and $M L$ in millimeters relative to the midline. ILn lesions were made by injections at AP 7.2, $\mathrm{ML} \pm 1.4$, DV 4.0; AP 6.2, ML \pm 1.4 , DV 4.0; AP 5.2, $\mathrm{ML} \pm 1.6$, DV 4.0; AP 7.2, ML \pm 0.6 , DV 4.0; AP 6.2, ML \pm 0.6 , DV 3.6; and AP 5.2, ML \pm 0.6 , DV 3.6. VMn lesions were made by injections at AP 7.2, ML \pm 1.3 , DV 2.5; AP 6.2, ML \pm 1.3 , DV 2.5; and AP 5.2, $\mathrm{ML} \pm 1.3$, DV 2.8. LDn lesions were made by injections at AP 7.2, $\mathrm{ML} \pm 2.0, \mathrm{DV} 4.8 ; \mathrm{AP} 6.2, \mathrm{ML} \pm 2.0, \mathrm{DV} 4.8 ;$ and AP 5.2, $\mathrm{ML} \pm 1.6$, DV 5.0.

\section{Apparatus}

DMS was trained in six operant chambers (Med Associates, Georgia, VT) enclosed in ventilated wooden sound-insulating boxes. Each chamber was equipped with three retractable levers, two on the front wall on either side of a water dipper and one centered along the back wall. The dipper was raised to provide reinforcement $(0.1 \mathrm{ml}$ of tapwater) and was equipped with a photocell to record head entries made to gain access to the dipper. There was a houselight above the back lever that was illuminated throughout all behavioral training. The chamber was controlled through an interface (Med Associates) connected to a 486 computer.

\section{Behavioral Training}

Presurgical training. The procedures used to train DMS were based on those used by Burk and Mair (1998). After initial' shaping to press levers to receive reinforcement, the rats were trained to complete trials consisting of a sequence of four lever presses. Levers were extended one at a time (with the other two retracted) so that presses were made in the following sequence: back-lever press to initiate a trial, front-lever press (on whichever lever was presented), back-lever press, and then front-lever press (with the same lever extended as previously on that trial). Levers were retracted after a single press, and the next lever was extended. After the fourth lever press (on the front lever extended previously during that trial), the dipper was raised to provide reinforcement. The rats were trained until they reached a criterion of 60 trials during a 40-min session for two consecutive sessions.

DMS training was then begun by modifying the four-lever-press task so that both levers were extended at the time of the fourth press. Each trial thus began with the back lever extending. After this was pressed once, it was retracted and one of the two front levers was extended (the sample lever, randomly selected on a trial-by-trial basis). After the sample lever was pressed, it was retracted and the 
back lever was extended. Pressing the back lever then caused it to retract and the two front levers to extend to initiate the choice response. If the rat next pressed the sample lever (the front lever extended and pressed previously on that trial), reinforcement was given by raising the dipper and a correct DMS response was recorded. If the rat pressed the other lever (an incorrect nonmatching response), reinforcement was withheld, an error was recorded, and a correction trial was run. A correction trial was a repeat of the preceding trial on which an error was made. There was a maximum of two consecutive correction trials, and these were not included in analyses of response speed or accuracy or in counts of the total trials/session. The intertrial interval was $3.0 \mathrm{sec}$ during this phase of training. Training was continued until the rats reached a criterion of $80 \%$ correct for two consecutive sessions.

After the rats reached this criterion, the DMS procedure was changed in two ways. First, the sample response criterion was increased to fixed ratio 2 (FR2) or FR7. Thus, on half the trials, the sample lever had to be pressed twice, and, on half, it had to be pressed seven times before it was retracted. The choice of the FR2 or FR7 response requirement was made randomly on a trial-by-trial basis. Second, the retention interval was varied by introducing a delay of $1,3,8$, or $13 \mathrm{sec}$ (selected randomly on a trial-by-trial basis) before a press on the back lever, extended after completion of the sample response, would initiate the choice response. These training sessions lasted until 40 trials were completed or a maximum of $75 \mathrm{~min}$ had elapsed. Presurgical training continued until the rats reached a criterion of $75 \%$ correct averaged across retention intervals and sample requirement conditions.

Postsurgical training. After $8-10$ days of postsurgical recovery, the water-deprivation schedule was reinstated. Two days later, we began postsurgical training, using the same procedures followed immediately before surgery for the first 25 sessions. DMS performance was measured by percent correct and by the time required to (1) complete the sample requirement after the trial was initiated (i.e., the interval between the first and second responses), (2) initiate the choice response by pressing the back lever after completion of the retention interval (i.e., the interval between the second and third responses minus the imposed retention interval), and (3) complete a choice response after it was initiated (i.e., the interval between the third and fourth responses).

After the first 25 sessions of postsurgical training, the DMS task was changed to include a wider range of retention intervals $(1,6$, 12,18 , and $24 \mathrm{sec}$ ) and to reduce the sample requirement to one press for all trials. DMS was trained in this manner for 25 additional sessions using the same dependent measures as in the first 25 postsurgical sessions.

To test the generality of the lesion effects, we next trained the rats to perform a series of eight reversal learning problems using procedures such as those described by Burk and Mair (1998). Serial reversal learning trials began with the extension of the back lever. After this lever was pressed, the back lever retracted and both front levers were extended. For each session, one of the two front levers was designated as $\mathbf{S}+$ and the other as $\mathbf{S}-$. Pressing the $\mathbf{S}+$ lever caused the front levers to retract and the dipper to be raised to provide reinforcement. Pressing the $S-$ lever caused the front levers to retract without reinforcement. Like DMS, the reversal learning problems required the rats to respond to one of two extended levers for reinforcement with $0.1 \mathrm{ml}$ of tapwater. Unlike DMS, correct responding did not require the rats to update and remember information on a trial-by-trial basis. Each session lasted until either 100 trials were completed or the rats reached a criterion of 15 consecutive correct $(\mathrm{S}+$ ) responses. If a criterion was reached, the problem was switched ( $\mathrm{S}+$ and $\mathrm{S}-$ designations were reversed) for the next session. Serial reversal learning was continued until the rats reached criterion for the initial problem and seven subsequent reversals. Performance was measured by the number of errors made before criterion was reached for each of the problems.

\section{Histological Analyses}

At the end of the experiment, the rats were killed under deep anesthesia ( $100 \mathrm{mg} / \mathrm{kg}$ ketamine, $10 \mathrm{mg} / \mathrm{kg}$ xylazine, i.m.) by transcardiac perfusion of physiological saline followed by $5 \%(v / v)$ neutral buffered formalin. Brains were cryoprotected by subsequent immersion in solutions of $10 \%$ glycerin $/ 4 \%$ neutral buffered formalin for 1 day and then $20 \%$ glycerin $/ 4 \%$ neutral buffered formalin for at least 3 days. Tissue was sectioned frozen in the coronal plane at $30 \mu \mathrm{m}$. Every fifth section was then mounted and stained with cresyl violet for histological verification of the extent of the lesions.

\section{RESULTS}

\section{DMS Accuracy}

Prior to surgery, there were no significant differences in the performances of the rats assigned to the different surgical treatments $(F<1)$. During the first 25 sessions of postsurgical training, the ILn group was substantially
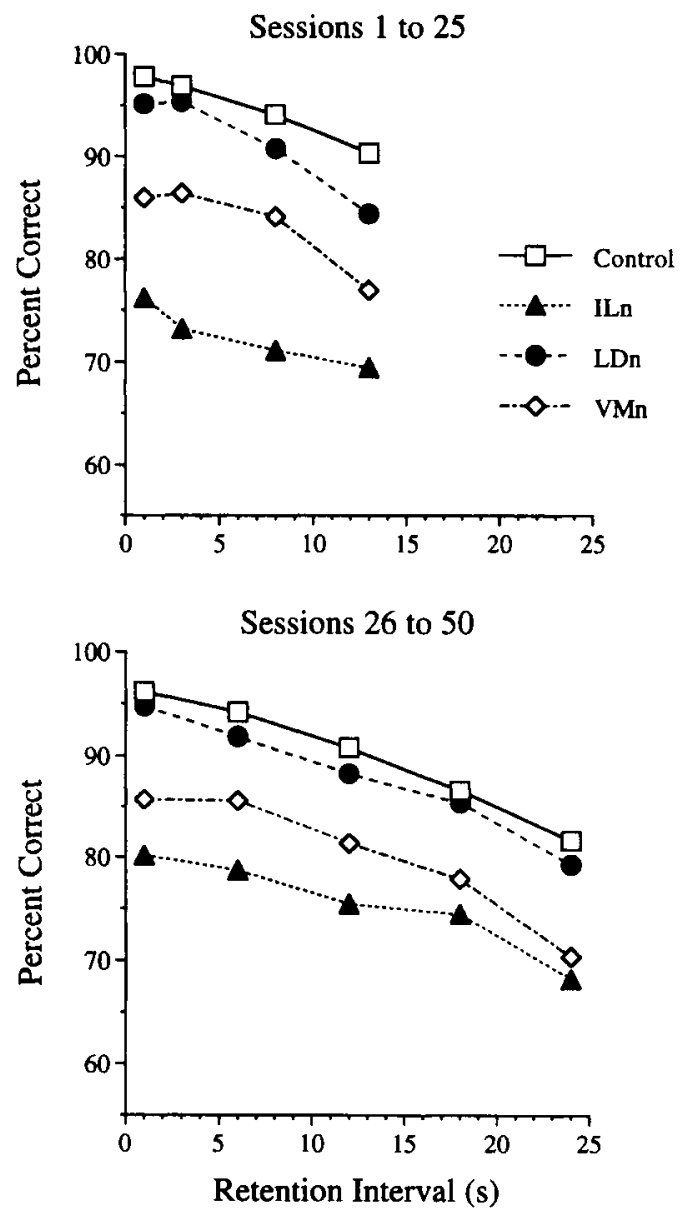

Figure 1. Temporal decay of delayed matching-to-sample (DMS) accuracy as measured by percent correct. Both the ILn group and the VMn group show signs of a delay-independent impairment. The upper graph shows results for the first 25 sessions when the animals were trained at retention intervals from 1.0 to $13.0 \mathrm{sec}$. The lower graph shows results from Sessions 26-50 when animals were trained at retention intervals from 1.0 to $\mathbf{2 4 . 0}$ sec. ILn, intralaminar nucleus lesion; LDn, laterodorsal nucleus lesion; VMn, ventromedial nucleus lesion. 
impaired, averaging $72.5 \%$ correct, compared with $83.4 \%$ correct for the VMn group, $91.4 \%$ correct for the LDn group, and $94.8 \%$ correct for the control group. The forgetting functions for the four groups appeared to be parallel, with each group tending to perform less accurately at longer retention intervals (Figure 1). These results were confirmed by a two-factor (treatment group $X$ retention interval) analysis of variance (ANOVA) that showed significant main effects for treatment $[F(3,36)=$ $13.379, p<.0001]$ and retention interval $[F(3,108)=$ $34.543, p<.0001]$, but not for the interaction of these two factors $[F(9,108)=1.234, p=.2820]$. Post hoc analysis (Student-Newman-Keuls, $\alpha=.05$ ) showed that the ILn group was impaired relative to the other three treatment groups and that the VMn group was impaired relative to the control and the LDn groups.

There was a tendency for all groups to perform better when the sample requirement was increased from FR2 to FR7 $(85.1 \% \times 86.3 \%$ correct). A two-factor (sample requirement $\times$ treatment group) ANOVA showed that this difference was statistically significant $[F(1,36)=$ $10.017, p=.0032]$, although its interaction with treatment was not $[F(3,36)=2.160, p=.1097]$.

The treatment effects observed during the first 25 postsurgical sessions were little changed when retention intervals were increased during Sessions 26-50 after surgery. The ILn group averaged $75.3 \%$ correct, compared with $80.2 \%$ correct for the VMn group, $87.9 \%$ correct for the LDn group, and $89.9 \%$ correct for the controls. Again, all groups tended to perform more poorly as the retention interval was increased, and these forgetting functions were parallel to each other (Figure 1). These trends were verified by a two-factor (treatment group $X$ retention interval) ANOVA that showed significant main effects for treatment $[F(3,36)=8.323, p=.0002]$ and retention interval $[F(4,144)=94.237, p<.0001]$, but not for the interaction of these factors $(F<1)$. Post hoc analysis (Student-Newman-Keuls, $\alpha=.05$ ) showed that both the ILn group and the VMn group were impaired relative to the LDn and control groups but did not differ from each other.

\section{DMS Speed}

Response speed was measured in two ways. First, we measured the latency from the end of the retention interval until a choice response was made. This was done to provide a direct comparison with analyses described in previous reports (Burk \& Mair, 1998; Knoth \& Mair, 1991; Mair et al., 1998; Mair \& Lacourse, 1992). The results of this analysis are shown in Figure 2 as cumulative plots (as in previous studies). For both blocks of sessions, the ILn-lesioned rats made relatively few of their responses at short latencies, relative to control or to LDn-lesioned rats. The VMn group exhibited an intermediate level of impairment during the first block of 25 sessions and an equivalent level of impairment during the second block.

These data were analyzed by one-way ANOVAs using median response time as the dependent measure. For the first block of 25 sessions, there was a significant difference among the treatment groups $[F(3,36)=6.543, p=$ .0012 ]. Post hoc analysis (Student-Newman-Keuls, $\alpha=$ .05 ) showed that the ILn group was impaired relative to the other three treatment groups and that the VMn, LDn, and control groups did not differ from each other. For the
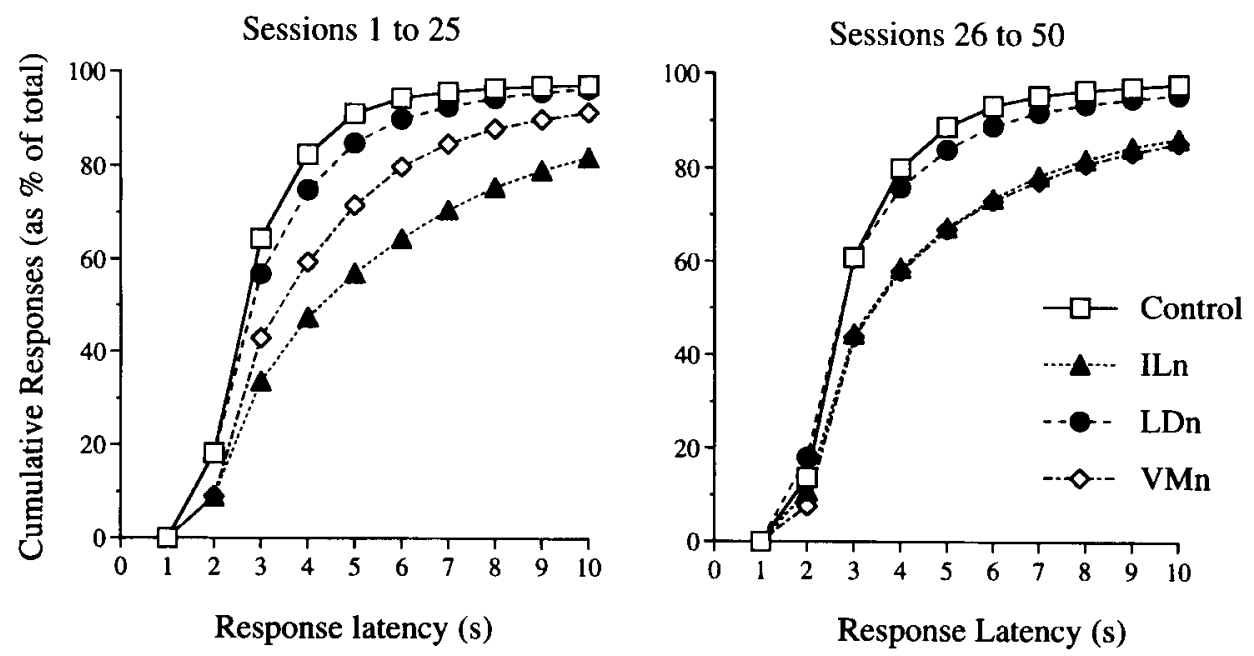

Figure 2. Latency of delayed matching-to-sample (DMS) responding plotted as a cumulative function of time. Latency was measured for every response from the time when the retention interval ended until a DMS choice response was made. Results are shown separately for each of the two blocks of 25 sessions in which DMS was trained postsurgically (as in Figure 1). While the LDn animals performed comparably to controls, the ILn and VMn groups tended to make more frequent long latency responses. ILn, intralaminar nucleus lesion; LDn, laterodorsal nucleus lesion; VMn, ventromedial nucleus lesion. 
second block of 25 sessions, the group differences only approached statistical significance $[F(3,36)=4.801$, $p=.0608]$.

As in previous studies (Burk \& Mair, 1998; Knoth \& Mair, 1991; Mair \& Lacourse, 1992), DMS responses made at a long latency $(>3.0 \mathrm{sec})$ from the end of the retention interval tended to be less accurate than those made at a shorter latency $(<3.0 \mathrm{sec})$; however, there did not seem to be an interaction between the effects of lesions on speed and accuracy (Figure 3). Thus, ILn and VMn lesions had similar effects when analyses were restricted to either short- or long-latency responses. These trends were verified by two-factor (response latency $x$ treatment group) ANOVAs in which percent correct was
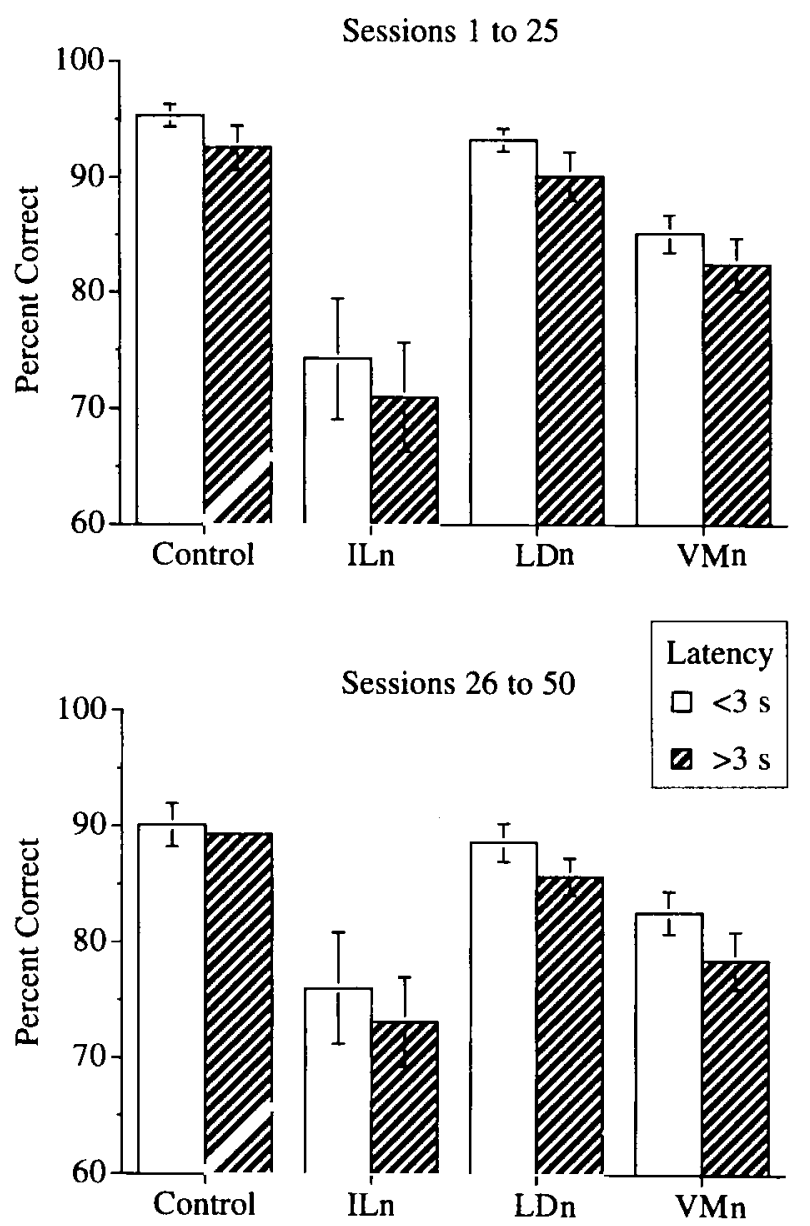

Figure 3. The accuracy of long ( $>3.0 \mathrm{sec}$ ) and short $(<3.0 \mathrm{sec})$ latency delayed matching-to-sample (DMS) responses. Latency was measured as in Figure 2. By using $3.0 \mathrm{sec}$ as the dividing point, the short latency analyses were restricted to a narrow range of responding (from 1.0 to $3.0 \mathrm{sec}$ after the retention interval) and yet included $63 \%$ of responses for controls, $59 \%$ for LDn, $43 \%$ for VMn, and $39 \%$ for ILn animals. Restricting analyses to short latency responses had little effect on the extent of impairments observed for response accuracy (percent correct) among ILn- and VMn-lesioned animals. Error bars represent standard error of the mean. ILn, intralaminar nucleus lesion; LDn, laterodorsal nucleus lesion; VMn, ventromedial nucleus lesion. the dependent variable. For the first 25 sessions, there were significant main effects for response latency $[F(1,36)$ $=16.098, p=.0003]$ and treatment group $[F(3,36)=$ $11.974, p<.0001]$, but not for the interaction of these factors $(F<1)$. For the second block of 25 sessions, there were significant main effects for response latency $[F(1,36)$ $=8.516, p=.0060]$ and treatment group $[F(3,36)=$ $7.459, p=.0005]$, but not for the interaction $(F<1)$.

The second set of analyses of response speed was designed to compare the effects of lesions on different components of the DMS task. Each DMS trial involved four discrete responses: pressing the back lever to initiate a sample response, completing the sample response on the front lever next extended, pressing the back lever after completion of the retention interval to initiate the choice response, and completing the choice response by pressing one of the two front levers next extended. For this analysis, we measured the time required (1) to execute a sample response after a trial was initiated by a press on the back lever, (2) to initiate a choice response by pressing the back lever after the retention interval ended, and (3) to execute a choice response after it was initiated by a press on the back lever.

The second set of analyses showed that the effects of ILn and VMn lesions on response speed extended to all of the components of DMS responding that we measured (Figure 4). All groups tended to take more time to execute sample responses than to initiate or to execute the choice responses. Not surprisingly, there was a tendency for sample responses to take longer during the first 25 sessions, when there were response requirements of FR2 or FR7, than during the last 25 sessions, when the sample response requirement was reduced to a single lever press (comparable to the choice response requirement throughout all 50 sessions). For the first 25 sessions, a two-factor (treatment group $\times$ response component) ANOVA showed significant main effects for treatment group $[F(3,36)=7.491, p=.0005]$ and response component $[F(2,72)=99,235, p<.0001]$ and for the interaction between these factors $[F(6,72)=6.498, p<$ .0001 ]. Post hoc analysis (Student-Newman-Keuls, $\alpha=$ $.05)$ showed that the ILn and VMn groups were slower than the control and LDn groups. The significant interaction was followed up by measuring simple main effects with one-factor ANOVAs comparing treatment effects for each of the three response components. Group differences were significant for times required to execute the sample response $[F(3,36)=7.10, p=.0007]$ and to initiate the choice response $[F(3,36)=6.836, p=.0009]$, but not for executing the choice response $[F(3,36)=$ $2.626, p=.0652]$.

For the second block of 25 sessions, a two-factor (treatment group $\times$ response component) ANOVA again showed significant main effects for treatment group $[F(3,36)=6.450, p=.0013]$ and response component $[F(2,72)=136.574, p<.0001]$ and for the interaction between these factors $[F(6,72)=5.224, p=.0002]$. Post hoc analysis (Student-Newman-Keuls, $\alpha=.05$ ) 

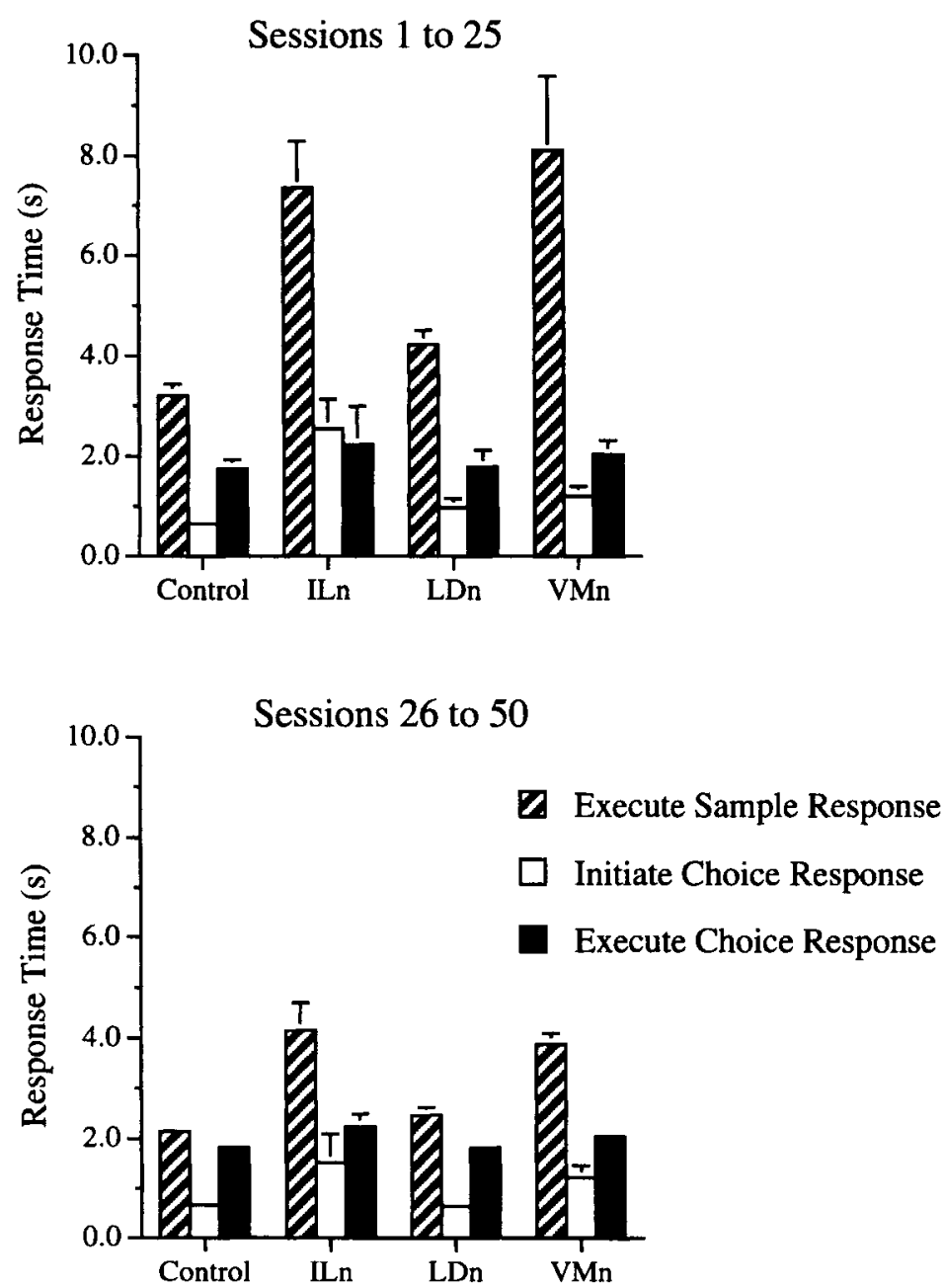

Figure 4. Mean response time for executing sample responses (the interval from the back lever press initiating the trial until completion of the sample response requirement), initiating the choice response (the interval between the end of the imposed retention interval and the press on the back lever setting up a choice response), and executing a choice response (the interval between the back lever press initiating the choice response at the end of the retention interval until one of the two front levers is pressed as a choice response). The ILnand VMn-lesioned animals tended to respond slowly during all phases of the DMS task. Error bars represent standard error of the mean. ILn, intralaminar nucleus lesion; LDn, laterodorsal nucleus lesion; VMn, ventromedial nucleus lesion.

showed that the ILn and VMn groups were slower than the control and LDn groups. The significant interaction was followed up by measuring simple main effects with one-factor ANOVAs comparing treatment effects for each of the three response components. Group differences were significant for time to respond to execute the sample response $[F(3,36)=11.234, p<.0001]$, but not for the time to either initiate $[F(3,36)=2.027, p=$ $.1212]$ or execute $[F(3,36)=1.969, p=.1361]$ the choice response. Thus, for both blocks of 25 sessions, there was a significant interaction that seemed to reflect a greater effect of lesions on the time required to make sample re- sponses than on the time taken to either initiate or execute choice responses.

\section{Serial Reversal Learning}

All of the rats were able to perform each of the eight problems at the criterion of 15 consecutive errorless responses. Although there was a trend for the ILn group to make more errors than the VMn, LDn, and control groups ( 42.8 vs. $34.4,24.9$, and 29.7 , respectively), this did not prove to be statistically significant. A two-factor (treatment group $\times$ SRL problem) ANOVA did not reveal significant differences for treatment group $[F(3,36)=2.284$, 


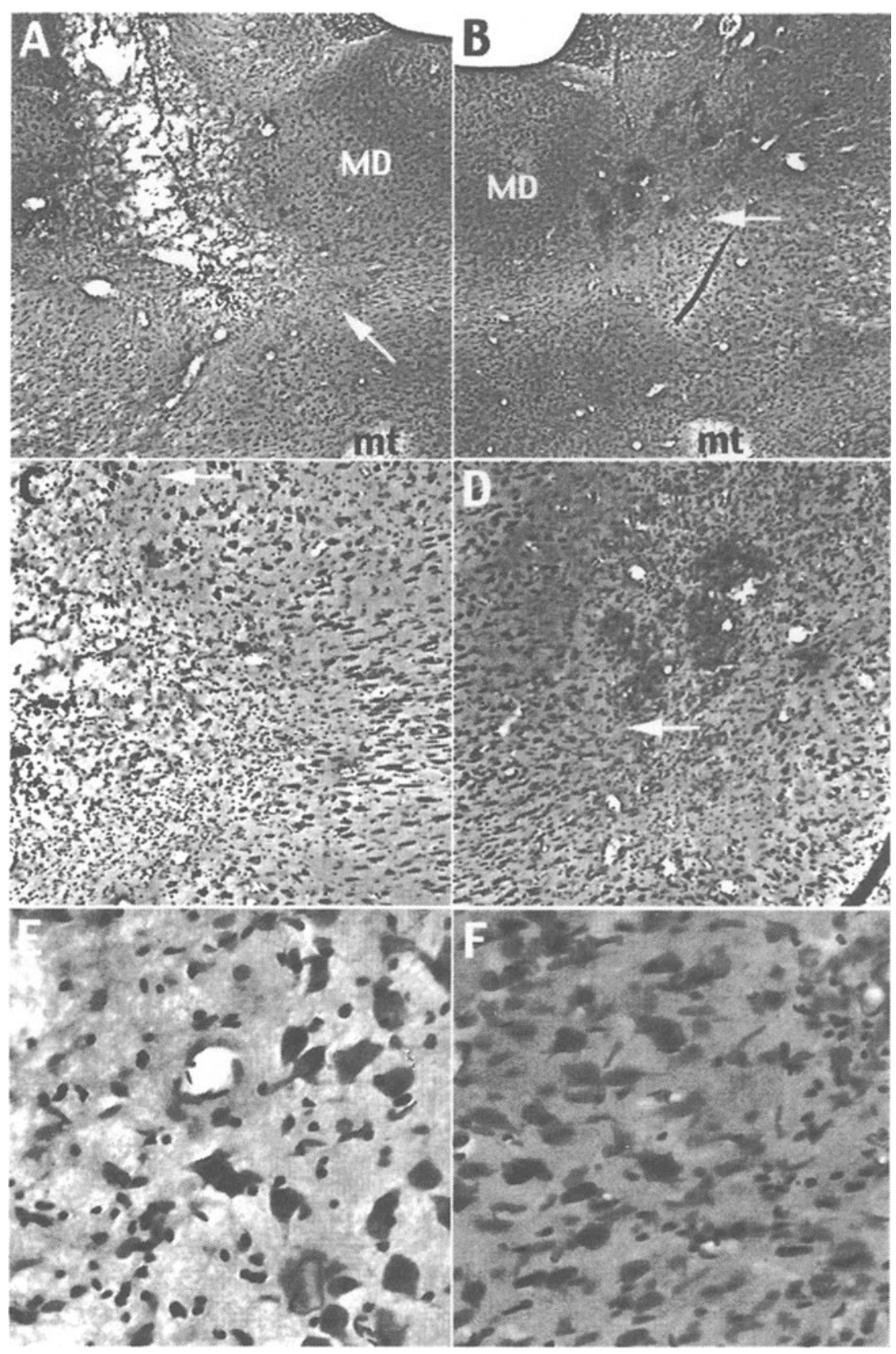

Figure 5. Photomicrographs showing an example of an intralaminar nuclei (ILn) lesion. Low power photomicrographs ( $A$ and $B$ ) are from the right and left sides of the same coronal section of tissue about $6.2 \mathrm{~mm}$ anterior to the interaural line. The arrows indicate the location of higher power photomicrographs shown below (i.e., the arrow in $A$ shows the location of $\mathrm{C}$ and the arrow in $\mathrm{C}$ shows the location of $\mathrm{E}$ ). $\mathrm{MD}$, mediodorsal nucleus; $\mathrm{mt}$, mammillothalamic tract. The habenula is just visible at the top of $A$ and $B$.

$p=.0954]$ or SRL problem $[F(7,252)=1.918, p=.0671]$ or for the interaction of these factors $[F(21,252)=1.144$, $p=.3030]$.

\section{Histological Results}

All surgical lesions affected their intended targets. The ILn lesions affected the paracentral and centrolateral nuclei in all 10 cases and adjacent portions of the central medial (CM) nuclei in 8 of 10 cases (Figure 5). Midline areas of $\mathrm{CM}$ were spared in 6 of the 10 cases. Unintended damage was observed in thalamic nuclei adjacent to the ILn, including medial and lateral portions of the mediodorsal nuclei ( 8 cases), medial portions of LDn ( 5 cases), overlying areas of hippocampus ( 3 cases) and posterior portions $(<7.4 \mathrm{~mm}$ from IA) of the anteromedial ( 6 cases), and the anteroventral and anterodorsal nu- 

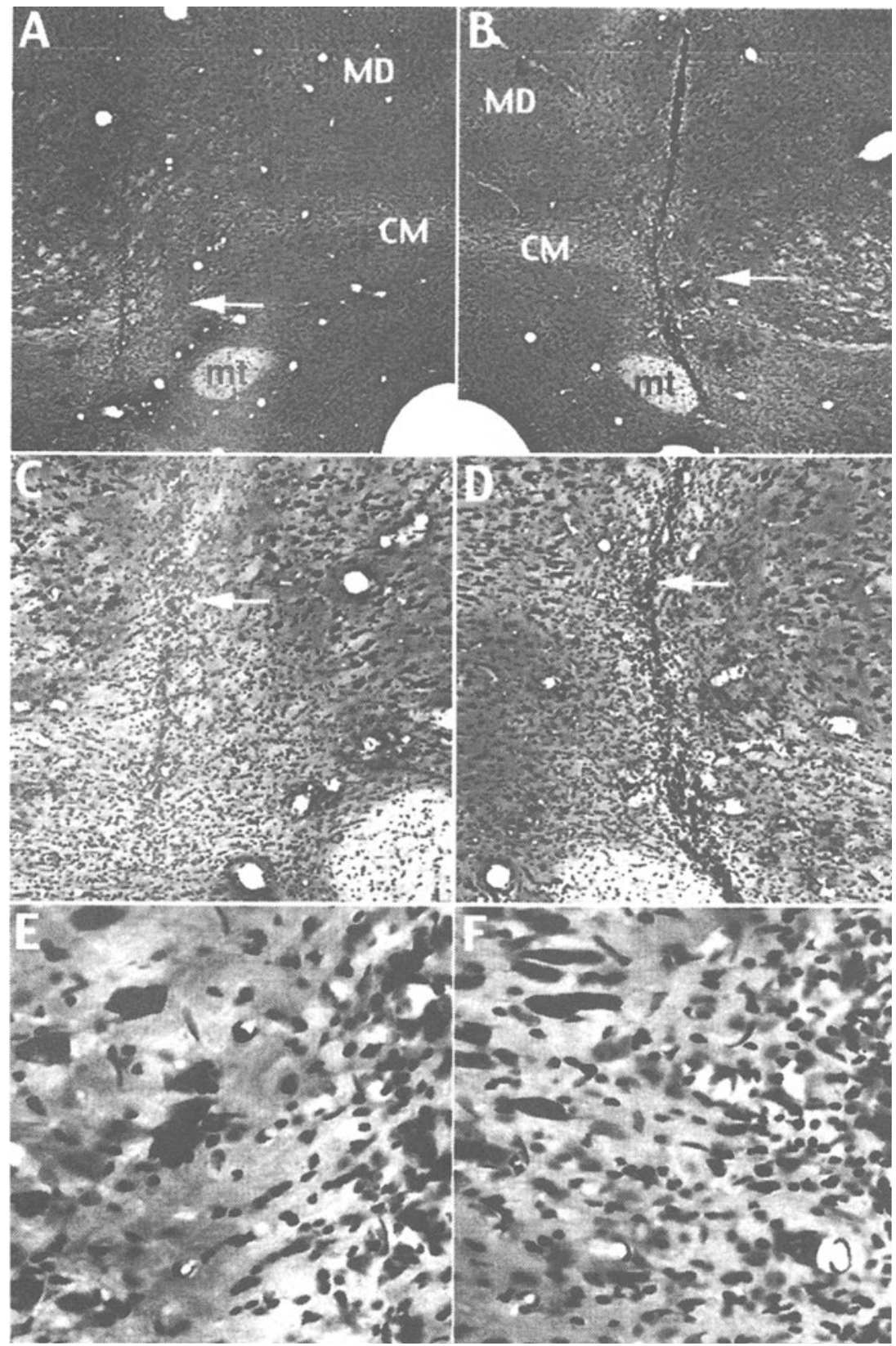

Figure 6. Photomicrographs showing an example of a ventromedial nucleus (VMn) lesion. Low power photomicrographs ( $A$ and $B$ ) are from the right and left sides of the same coronal section of tissue about $6.2 \mathrm{~mm}$ anterior to the interaural line. The arrows indicate the location of higher power photomicrographs shown below (i.e., the arrow in $A$ shows the location of $\mathrm{C}$ and the arrow in $\mathrm{C}$ shows the location of $\mathrm{E}$ ). Note the spread of pathology in a dorsal direction along the apparent location of the cannula used to infuse the excitotoxin into the region of the paracentral and centrolateral nuclei. $\mathrm{MD}$, mediodorsal nucleus; $\mathrm{CM}$, centromedial nucleus; mt, mammillothalamic tract.

clei (all cases) adjacent to the paracentral or centrolateral nuclei.

The VMn lesions were associated with bilateral damage of VMn in all 10 cases (Figure 6). These lesions tended to affect limited portions of adjacent nuclei, including the paracentral and centrolateral nuclei in 8 (of 10) cases,
LDn in 4 cases, and overlying areas of hippocampus in 3 cases. Although the paracentral and centrolateral nuclei were involved in almost every case, these lesions were typically limited to areas immediately adjacent to the cannula track (see Figure 6) and were thus much more limited than observed for the ILn lesions. Only 1 case was 
observed in which the mediodorsal and CM nuclei were involved.

The LDn lesions affected their intended target in all 10 cases (Figure 7). In all cases, these lesions also affected the lateral posterior nucleus behind LDn extending at least to the posterior margin of the mediodorsal nucleus (or the point where fasciculus retroflexus extends below habenula in coronal section) and posterior portions ( $<7.4 \mathrm{~mm}$ from IA) of the anteroventral and anterodorsal nuclei. In 7 cases, LDn lesions extended ventrally to affect tissue within the ventrolateral and posterior nuclei lateral to the paracentral and centrolateral

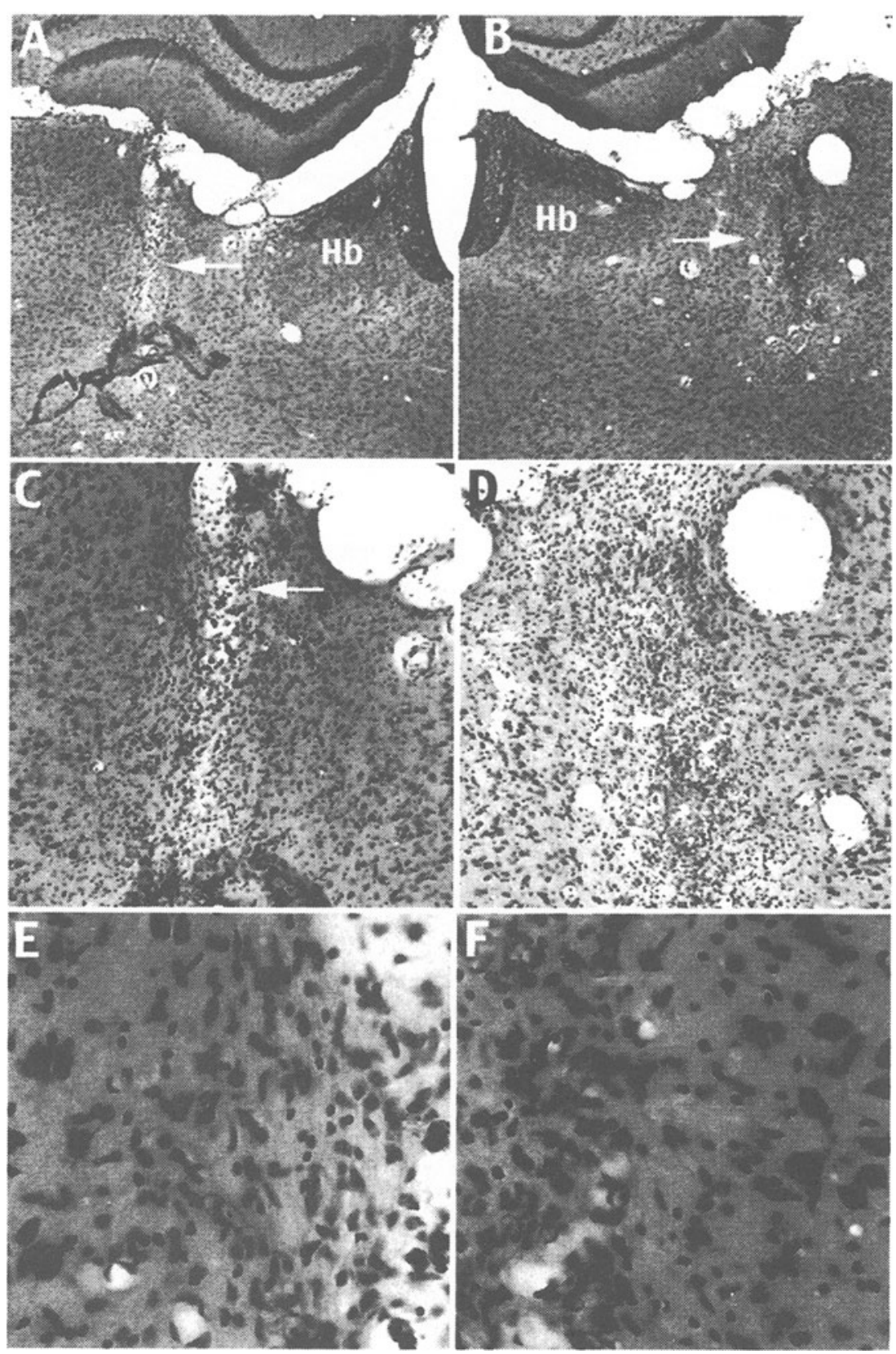

Figure 7. Photomicrographs showing an example of a laterodorsal nucleus (LDn) lesion. Low power photomicrographs (A and B) are from the right and left sides of the same coronal section of tissue about $6.2 \mathrm{~mm}$ anterior to the interaural line. The arrows indicate the location of higher power photomicrographs shown below (i.e., the arrow in $A$ shows the location of $C$ and the arrow in $C$ shows the location of $E$ ). Note the spread of pathology beyond the ventral border of LDn. Hb, habenula. 
nuclei. In 6 cases, damage was observed in overlying areas of hippocampus.

\section{DISCUSSION}

\section{The ILn and DMS Accuracy}

The rats with ILn lesions made significantly more errors performing the DMS task than did the controls or the rats with LDn or VMn lesions. The size of this deficit is consistent with the impairment observed on the same task when the ILn were damaged by infusing larger volumes of a 100-mM NMDA solution at more ventral stereotaxic coordinates (Burk \& Mair, 1998). ILn-lesioned rats in this earlier study averaged $61.6 \%$ correct, compared with $86.1 \%$ correct for controls over the first 25 sessions of postsurgical training. In the present study (with comparable conditions and training trials), the rats with ILn lesions averaged $72.5 \%$ correct, compared with $94.8 \%$ correct for the controls. In both studies, the effects of ILn lesions on DMS were independent of the length of the retention interval. The delay-independence of these impairments is consistent with findings for other delayed conditional discrimination tasks for ILn pathology associated with pyrithiamine-induced thiamine deficiency (Robinson \& Mair, 1992), radiofrequency lesions (Young, Stevens, Converse, \& Mair, 1996), or NMDA infusions (Mair et al., 1998; Zhang et al., 1998).

The effects of ILn lesions on serial reversal learning in the present study were also consistent with the findings of Burk and Mair (1998). All rats were able to reach a criterion of 15 consecutive correct responses for an initial discrimination and for seven subsequent reversal problems. While the ILn-lesioned rats tended to make more errors reaching these criteria ( 42.8 errors to criteria vs. 29.7 for controls in the present study; 40.6 errors to criteria vs. 19.0 for controls in Burk \& Mair, 1998), these differences were not statistically significant. The ability to learn each of the problems to an errorless criterion demonstrates a preserved capacity for reference memory needed to perform procedural aspects of the lever press task and to respond consistently in selecting one of the two front levers in a forced choice contingency. Similar results have been reported for rats with ILn pathology associated with pyrithiamine-induced thiamin deficiency (Mair, Knoth, Rabchenuk, \& Langlais, 1991) or with radiofrequency lesions aimed at lateral portions of the internal medullary lamina (Harrison \& Mair, 1996).

Excitotoxic lesions of the ILn have been associated with coincidental damage to adjacent structures, including the VMn and the LDn, as well as the mediodorsal, the lateral posterior, and the anterior nuclei. The involvement of these adjacent nuclei seem an inevitable consequence of lesioning the full extent of the ILn. Of these adjacent structures, only the VMn has been associated with DMS impairment. In an earlier report, lesions of the mediodorsal nucleus were found to have little effect on DMS accuracy: rats with mediodorsal lesions performed comparably to controls $(82.0 \%$ vs. $86.1 \%$ correct for controls) at a level significantly better than rats with ILn lesions (61.6\% correct; Burk \& Mair, 1998). In the present study, DMS performance was impaired by lesions of the VMn that spared the mediodorsal nucleus but involved the ILn (albeit in a limited fashion). Rats with mediodorsal lesions have been found to be unimpaired relative to controls and significantly better than rats with lesions affecting the ILn for two other measures of remembering: DNMS based on positional cues (Young et al., 1996) and olfactory continuous DNMS (Zhang et al., 1998). Even though lesions of the mediodorsal nucleus alone have not had significant effects on these DMS and DNMS tasks, the consistent involvement of this nucleus in complete ILn lesions allows the logical possibility that both the ILn and the mediodorsal nuclei must be damaged to impair these measures of working memory.

The LDn lesion affected portions of the LDn, the lateral posterior, and the anterodorsal and anteroventral nuclei adjacent to the centrolateral nucleus that are typically damaged by ILn lesions (present study; see also Burk \& Mair, 1998). Given the limited effects of LDn lesions on DMS performance $(91.4 \%$ correct vs. $94.8 \%$ correct for controls), it seems unlikely that damage to these nuclei alone can account for the effects of ILn lesion on DMS performance. The LDn has been related anatomically and functionally to the hippocampal system (Mizumori et al., 1994; Mizumori \& Williams, 1993; van Groen \& Wyss, 1992). Previous studies have shown that the DMS task is not affected by hippocampal lesions (Mair et al., 1998). By contrast, reversible lesions of LDn have been shown to disrupt performance of a spatial memory task trained in a radial arm maze (Mizumori et al., 1994) that resembles tasks known to be sensitive to hippocampal system lesions (Jarrard, 1993; Mair et al., 1998). Thus, while we found little effect of LDn lesions on a task that is insensitive to hippocampal damage (lever press DMS), Mizumori et al. (1994) found reversible LDn lesions to disrupt performance of a task thought to be dependent on normal hippocampal function.

The VMn lesion was associated with an intermediate level of impairment ( $83.4 \%$ correct), significantly worse than for control or LDn lesions, but significantly better than for the ILn lesion. Unlike the ILn lesion, the effects of the VMn lesion were not confounded with incidental damage to the mediodorsal nucleus. The mediodorsal nucleus was affected in only 1 rat in the VMn group, and this rat actually performed slightly better than the group mean ( $84.6 \%$ vs. $83.4 \%$ correct). Excluding this rat from the analyses had little effect on the outcome of the statistical tests. VMn lesions were associated with consistent ILn damage, in the vicinity of the cannula track within the paracentral and centrolateral nuclei. Even though the extent of this damage was much less than that associated with ILn lesions, the consistency of its occurrence makes it difficult to rule out this involvement of the ILn as a possible cause of the DMS impairments associated with the VMn lesions. The possible involvement of VMn in DMS is of interest in view of the prominent projections of 
the ILn to striatum and of basal ganglia to the VMn and the evidence that ventral striatum plays an important role in this task (see below).

Savage, Sweet, Castillo, and Langlais (1997) reported that relatively extensive radio frequency lesions of the lateral internal medullary lamina are associated with signs of gliosis and neuronal loss in the mammillary bodies and anteroventral nucleus. Examination of the histological material in the present study found consistent involvement of the anteroventral and anterodorsal nuclei adjacent to intended lesion sites in both the ILn group and the LDn group but no signs of pathology in the mammillary bodies following any surgical treatment. It is unlikely that the observable damage in the anterior nuclear groups or any undetected pathology in the mammillary bodies can account for the DMS impairments associated with ILn or VMn lesions. In a previous study, we found that complete lesions of hippocampus did not significantly affect this same task (Mair et al., 1998). In the present study, the LDn lesions involved the anterior nuclear groups but did not have a significant effect on DMS performance. Other studies have shown that DNMS tasks based on positional cues are affected by lesions involving the ILn, but not by lesions of dorsal hippocampus, fornix, or mammillary bodies (Mair \& Lacourse, 1992; Young et al., 1996). Taken together, there is little evidence to suggest that damage to hippocampalrelated pathways or nuclei underlie DMS deficits observed following ILn or VMn lesions.

\section{Response Speed}

The rats with ILn lesions tended to respond slowly on the DMS task, making more of their choice responses at relatively long latencies from the end of the retention interval (Figure 2). This effect is consistent with findings for comparable DMS and DNMS tasks in previous studies of pyrithiamine-induced thiamin deficiency (Knoth \& Mair, 1991), radiofrequency lesions of the lateral internal medullary lamina (Mair \& Lacourse, 1992), and local infusion of NMDA into the ILn (Burk \& Mair, 1998). As in previous studies, there was a tendency for responses made at short latencies $(<3.0 \mathrm{sec}$ from the end of the retention interval) to be more accurate than responses made at longer latencies for all groups of animals (Figure 3). While the tendency to respond slowly may have contributed to the impairment observed for DMS accuracy, it does not appear to account for this deficit. Treatment effects were little changed when long-latency $(>3.0 \mathrm{sec})$ responses were eliminated (Figure 3 ), essentially limiting analyses to responses made from 1 to $3 \mathrm{sec}$ after the end of the retention interval (see Figure 2).

Previous analyses of DNMS or DMS response speed have focused on the time taken to make a choice response after the end of the retention interval. We measured the length of the intervals between each of the lever presses in the DMS task to provide a more complete picture of the time taken to complete this task. The results showed a greater treatment effect for the time to make the sam- ple response than for the time to initiate or to make the choice response. This result was confirmed by significant treatment group $\times$ response component interactions and subsequent analyses of simple main effects. For the first block of sessions, this trend may have reflected the larger response requirement of two or seven lever presses for sample responses, compared with only a single press for initiating or making the choice response. For the second block of 25 trials, however, the sample response requirement was reduced to a single lever press and thus was equivalent to the other response components.

Sample responses simply required the rats to press whichever front lever was extended after the back lever was retracted. Choice responses were similar except that the rats had to select between two extended levers, based on a DMS contingency, before executing a lever press. If the slow DMS responding associated with the ILn lesion was caused by an inability to perform a conditional choice such as DMS, then the effect of this lesion on response speed should have been greater for the choice response. The finding of a diametrical result seems incompatible with this possibility. Given the similarity of the sample and choice responses, it seems unlikely that factors such as distractibility can account for the difference. It is logically possible that sample responses are more susceptible to lesion effects because of the longer delay to reinforcement. However, we know of no evidence to suggest that ILn or VMn lesions should have this effect. Another possibility is that the changes in response latency are related to the initiation of the sequence of responses involved in each DMS trial. This possibility is consistent with known effects of basal ganglia disease (see below).

\section{The ILn and the Basal Ganglia}

The ILn are a major source of afferents to the striatum. These projections are topographically organized, such that individual nuclei project to restricted areas of caudate-putamen and to areas of prefrontal cortex that are linked by corticostriatal pathways (Groenewegen \& Berendse, 1994). Thus, the ILn seem organized to exert control over cortical and striatal components of the distributed neural circuits (or "loops") that connect basal ganglia, thalamus, and cerebral cortex (Alexander, DeLong, \& Strick, 1986; Graybiel, 1995; Groenewegen, Wright, \& Uylings, 1997).

We have hypothesized that lesions of the ILn produce signs of amnesia through their effects on these corticobasal ganglia-thalamic pathways (Burk \& Mair, 1998; Mair et al., 1998). Lesions of dorsomedial prefrontal cortex have been associated with delay-independent impairments in response accuracy and slower response speeds for both DNMS (Harrison \& Mair, 1996; Young et al., 1996) and DMS (Mair et al., 1998) tasks in which the positions of levers or of response ports serve as discriminative stimuli. Other studies have shown that lesions involving dorsal areas of caudate-putamen that are innervated by dorsomedial prefrontal cortex (Berendse, Galis-de Graaf, \& Groenewegen, 1992; Sesack, Deutch, Roth, \& Bunney, 
1989) cause delay-independent impairments in accuracy for DMS trained with retractable levers (Dunnett, 1990). More recently, we have found that lesions of ventral striatum have effects on DMS accuracy and latency comparable to ILn lesions (Burk \& Mair, 1999).

The VMn receive important projections from the basal ganglia that originate within pars reticulata of the substantia nigra and the entopeduncular nucleus and project diffusely to prefrontal cortex (Faull \& Mehler, 1985; Herkenham, 1979; Jones, 1985). In the present study, the rats with VMn lesions exhibited delay-independent impairments of DMS accuracy and latency qualitatively similar to, although less severe than, the rats with ILn lesions. The similarity of these findings with results for striatal and prefrontal lesions (Burk \& Mair, 1999; Dunnett, 1990; Mair et al., 1998) is consistent with the hypothesis that DMS responding depends on the integrity of the neural circuits that connect the basal ganglia with prefrontal cortex. This evidence should be treated with caution, however, given the consistent involvement of overlying areas of the ILn in the VMn lesion (see above).

The effects of ILn lesions on response latency are suggestive of the bradykinesia, or slowness of moving most pronounced with the initiation of voluntary movements, that is a hallmark of Parkinson's disease (cf. Stacy \& Jankovic, 1992). We found that the ILn-lesioned rats were slow in making sample responses and thus in initiating the sequence of responses constituting a DMS trial. Current models of the basal ganglia relate these signs of bradykinesia to a loss of dopaminergic input that normally excites the direct projections of putamen to the internal segment of globus pallidus and pars reticulata of the substantia nigra (cf. Wichmann \& DeLong, 1996). In squirrel monkey, the ILn have been identified as an excitatory glutamatergic input to striatum (Sadikot, Parent, Smith, \& Bolam, 1992) that terminates preferentially on direct output pathways (Sidibé \& Smith, 1996). While comparable anatomical studies have not been carried out in rats, these results suggest a common mechanism-loss of excitatory input to the direct pathway--that may account for the slow responding associated with lesions of the ILn and with manipulations of dopaminergic activity in striatum (Amalric \& Koob, 1987).

The effects of the ILn lesion on the accuracy and speed of DMS responding resemble impairments observed for human Korsakoff syndrome patients. This disease has been shown to decrease the speed of responding in all but the simplest reaction time tasks, including tasks that require selection or dividing of attention (Talland, 1965), visual backward masking (Oscar-Berman, Goodglass, \& Cherlow, 1973), initiation of a practiced sequence of finger taps (Mair, Flint, Inhoff, \& Langlais, 1988), and delayed conditional discriminations such as DMS (OscarBerman \& Bonner, 1985; Oscar-Berman, Hutner, \& Bonner, 1992). Korsakoff's syndrome has been shown to disrupt the accuracy of responding for a variety of delayed conditional discrimination tasks (Aggleton, Nicol, Huston, \& Fairbairn, 1988; Oscar-Berman \& Bonner, 1985,
1989; Oscar-Berman et al., 1992; Squire, Zola-Morgan, \& Chen, 1988). Like ILn-lesions in rats (cf. Mair et al., 1998), Korsakoff's disease affects delayed conditional discriminations in multiple sensory modalities, even when performance is measured at minimal retention intervals (Oscar-Berman \& Bonner, 1989; Oscar-Berman et al., 1992). Unlike ILn-lesioned rats, these impairments seem to be delay-dependent. Thus, Korsakoff patients tend to show abnormally rapid decays in performance when the length of the retention interval is increased (Aggleton et al., 1988; Oscar-Berman \& Bonner, 1985, 1989; OscarBerman et al., 1992; Squire et al., 1988), whereas the impairment of ILn-lesioned rats performing DMS and DNMS tasks is little changed when the length of the retention interval is increased (Burk \& Mair, 1998; Mair et al., 1998; Zhang et al., 1998; present results).

\section{REFERENCES}

Aggleton, J. P., Nicol, R. M., Huston, A. E., \& Fairbairn, A. F. (1988). The performance of amnesic subjects on tests of experimental amnesia in animals: Delayed matching-to-sample and concurrent learning. Neuropsychologia, 26, 265-272.

Aggleton, J. P., \& SAHgal, A. (1993). The contribution of the anterior thalamic nuclei to anterograde amnesia. Neuropsychologia, 31 , $1001-1019$.

Alexander, G. E., DeLong,.M. R., \& Strick, P. L. (1986). Parallel organization of functionally segregated circuits linking basal ganglia and cortex. In M. W. Cowan, E. M. Shooter, C. F. Stevens, \& R. F. Thompson (Eds.), Annual review of neuroscience (Vol. 9, pp. 357 381). Palo Alto, CA: Annual Reviews.

AmalRic, M., \& KoOB, G. F. (1987). Depletion of dopamine in the caudate nucleus but not in nucleus accumbens impairs reaction-time performance in rats. Journal of Neuroscience, 7, 2129-2134

Berendse, H. W., Galis-de GraAf, Y., \& Groenewegen, H. J. (1992). Topographical organization and relationship with ventral striatal compartments of prefrontal corticostriatal projections in the rat. Journal of Comparative Neurology, 316, 314-347

Brion, S., \& Mikol, J. (1978). Atteinte du noyau lateral dorsal du thalamus et syndrome de Korsakoff alcoolique [Involvement of the lateral dorsal thalamic nucleus in alcoholic Korsakoff's syndrome]. Journal of the Neurological Sciences, 38, 249-261.

Burk, J. A., Glode, B. M., Porter, M. C., Pelletier, J. R., \& Mair, R. G. (1997). Place DMTS performance is impaired by discrete lesions of the intralaminar (IL) or ventromedial (VM) but not the laterodorsal (LD) thalamic nuclei. Society for Neuroscience Abstracts, 23, 1598 .

BuRK, J. A., \& MaIR, R. G. (1998). Thalamic amnesia reconsidered: Excitotoxic lesions of the intralaminar nuclei, but not the mediodorsal nucleus disrupt place DMTS performance in the rat (Rattus norvegicus). Behavioral Neuroscience, 112, 54-67.

BURK, J. A., \& MAIR, R. G. (1999). Effects of dorsal and ventral striatal lesions on delayed matching-to-sample based on positional cues: Implications for thalamic amnesia. Unpublished manuscript.

DunNetT, S. B. (1990). Role of prefrontal cortex and striatal output systems in short-term memory deficits associated with ageing, basal forebrain lesions, and cholinergic-rich grafts. Canadian Journal of Psychology, 44, 210-232.

Faull, R. L. M., \& Mehler, W. R. (1985). Thalamus. In G. Paxinos (Ed.), The rat nervous system (Vol. 1, pp. 129-168). Sydney: Academic Press.

Graff-Radford, N. R., Tranel, D., van Hoesen, G. W., \& Brandt, J. P. (1990). Diencephalic amnesia. Brain, 113, 1-25.

Graybiel, A. M. (1995). Building action repertoires: Memory and learning functions of the basal ganglia. Current Opinion in Neurobiology, 5, 733-741.

Groenewegen, H. J., \& Berendse, H. W. (1994). The specificity of 
the "nonspecific" midline and intralaminar thalamic nuclei. Trends in Neurosciences, 17, 52-57.

Groenewegen, H. J., Wright, C. I., \& UyLings, H. B. M. (1997). The anatomical relationships of the prefrontal cortex with limbic structures and the basal ganglia. Journal of Psychopharmacology, 11, 99-106.

HARRISON, L. M., \& MAIR, R. G. (1996). A comparison of the effects of frontal cortical and thalamic lesions on measures of spatial learning and memory in the rat. Behavioural Brain Research, 75, 195-206.

HERKENHAM, M. (1979). The afferent and efferent connections of the ventromedial thalamic nucleus in the rat. Journal of Comparative Neurology, 183, 487-518.

JARRARD, L. E. (1993). On the role of the hippocampus in learning and memory in the rat. Behavioral \& Neural Biology, 60, 9-26.

Jones, E. G. (1985). The thalamus. New York: Plenum.

KNOTH, R. L., \& MAIR, R. G. (1991). Response latency and accuracy on a pretrained nonmatching-to-sample task in rats recovered from pyrithiamine-induced thiamin deficiency. Behavioral Neuroscience, 105, 375-385.

Langlais, P. J., \& Savage, L. M. (1995). Thiamine deficiency in rats produces cognitive and memory deficits on spatial tasks that correlate with tissue loss in diencephalon, cortex and white matter. Behavioural Brain Research, 68, 75-89.

Langlais, P. J., Zhang, S.-X., \& Savage, L. M. (1996). Neuropathology of thiamine deficiency: An update on the comparative analysis of human disorders and experimental models. Metabolic Brain Disease, 11, 19-37.

MaIR, R. G. (1994). On the role of thalamic pathology in diencephalic amnesia. Reviews in the Neurosciences, $5,105-140$

Mair, R. G., Anderson, C. D., Langlais, P. J., \& McEntee, W. J. (1988). Behavioral impairments, brain lesions and monoaminergic activity in the rat following recovery from a bout of thiamin deficiency. Behavioural Brain Research, 27, 223-239.

MaIr, R. G., BURK, J. A., \& PORTER, M. C. (1998), Lesions of the frontal cortex, hippocampus, and intralaminar thalamic nuclei have distinct effects on remembering. Behavioral Neuroscience, 112, 772-792.

Mair, R. G., Flint, D., Inhoff, A., \& Langlais, P. J. (1988). Voluntary control of attention is impaired in Korsakoff's syndrome. Society for Neuroscience Abstracts, 14, 1044.

Mair, R. G., KNOTh, R. L., Rabchenuk, S. A., \& Langlais, P. J. (1991). Impairment of olfactory, auditory, and spatial serial reversal learning in rats recovered from pyrithiamine-induced thiamin deficiency. $B e$ havioral Neuroscience, 105, 360-374.

MaIR, R. G., \& LACOURSE, D. M. (1992). Radio-frequency lesions of the thalamus produce delayed-nonmatching-to-sample impairments comparable to pyrithiamine-induced encephalopathy in rats. Behavioral Neuroscience, 106, 634-645.

Mair, W. P. G., Warrington, E. K., \& Weiskrantz, L. (1979). Memory disorders in Korsakoff's psychosis: A neuropathological and neuropsychological investigation of two cases. Brain, 102, 749-783.

Malamud, N., \& Skillicorn, S. A. (1956). Relationship between the Wernicke and the Korsakoff syndrome. A.M.A. Archives of Neurology \& Psychiatry, 76, 585-596.

MARKOWITSCH, H. J. (1982). Thalamic mediodorsal nucleus and memory: A critical evaluation of studies in animals and man. Neumscience \& Biobehavioral Reviews, 6, 351-380.

MaRKowitsCH, H. J. (1991). Memory disorders after diencephalic damage. In W. C. Abraham, M. C. Corballis, \& K. G. White (Eds.), Memory mechanisms: A tribute to G. V. Goddard (pp. 175-194). Hillsdale, NJ: Erlbaum.

Mennemeier, M., Fennell, E., Valenstein, E., \& Heilman, K. M. (1992). Contributions of the left intralaminar and medial thalamic nuclei to memory: Comparisons and a case report. Archives of Neurology, 49, 1050-1058.

Mizumori, S. J. Y., MiYA, D. Y., \& WARD, K. E. (1994). Reversible inactivation of the lateral dorsal thalamus disrupts hippocampal place representation and impairs spatial learning. Brain Research, 644, 168-174.

Mizumori, S. J. Y., \& Williams, J. D. (1993). Directionally selective mnemonic properties of neurons in the lateral dorsal nucleus of the thalamus of rats. Journal of Neuroscience, 13, 4015-4028.
Oscar-Berman, M., \& Bonner, R. T. (1985). Matching and delayed matching-to-sample performance as measures of visual processing, selective attention, and memory in aging and alcoholic individuals Neuropsychologia, 23, 639-65I.

OsCar-Berman, M., \& Bonner, R. T. (1989). Nonmatching- (oddity) and delayed nonmatching-to-sample performance in aging, alcoholic, and alcoholic Korsakoff individuals. Psychobiology, 17, 424-430.

Oscar-Berman, M., Goodglass, H., \& Cherlow, D. G. (1973). Perceptual laterality and iconic recognition of visual materials by Korsakoff patients and normal adults. Journal of Comparative \& Physiological Psychology, 82, 316-321.

Oscar-Berman, M., Hutner, N., \& Bonner, R. T. (1992). Visual and auditory spatial and nonspatial delayed-response performance by Korsakoff and non-Korsakoff alcoholic and aging individuals. Behavioral Neuroscience, 106, 613-622.

Parkin, A. J., Rees, J. E., Hunkin, N. M., \& Rose, P. E. (1994). Impairment of memory following discrete thalamic infarction. Neumpsychologia, 32, 39-51.

Robinson, J. K., \& MaIR, R. G. (1992). MK-801 prevents brain lesions and delayed-nonmatching-to-sample deficits produced by pyrithiamine-induced encephalopathy in rats. Behavioral Neuroscience, 106, 623-633.

Sadikot, A. F., PARent, A., Smith, Y., \& Bolam, J. P. (1992). Efferent connections of the centromedian and parafascicular thalamic nucle in the squirrel monkey: A light and electron microscopic study of the thalamostriatal projections in relation to striatal heterogeneity. Journal of Comparative Neurology, 320, 228-242.

Savage, L. M., Sweet, A. J., Castillo, R., \& Langlais, P. J. (1997) The effects of lesions to thalamic lateral internal medullary lamina and posterior nuclei on learning, memory and habituation in the rat Behavioural Brain Research, 82, 133-147.

Sesack, S. R., Deutch, A. Y., Roth, R. H., \& Bunney, B. S. (1989) Topographical organization of the efferent projections of the medial prefrontal cortex in the rat: An anterograde tract-tracing study with Phaseolus vulgaris leucoagglutinin. Journal of Comparative Neurology, 290, 213-242.

SidibÉ, M., \& SMITH, Y. (1996). Differential synaptic innervation of striatofugal neurons projecting to the internal or external segments of the globus pallidus by thalamic afferents in the squirrel monkey. Journal of Comparative Neurology, 365, 445-465

Souire, L. R., Zola-Morgan, S., \& Chen, K. S. (1988). Human amnesia and animal models of amnesia: Performance of amnesic patients on tests designed for the monkey. Behavioral Neuroscience, 102 , $210-221$

STACY, M., \& JANKoviC, J. (1992). Clinical and neurobiological aspects of Parkinson's disease. In S. J. Huber \& J. L. Cummings (Eds.), Parkinson's disease: Neurobehavioral aspects (pp. 10-31). New York: Oxford University Press.

TAlland, G. A. (1965). Deranged memory. New York: Academic Press. Van Groen, T., \& Wyss, J. M. (1992). Projections from the laterodorsal nucleus of the thalamus to the limbic and visual cortices in the rat. Journal of Comparative Neurology, 324, 427-448.

Victor, M., AdAMS, R. D., \& Collins, G. H. (1989). The WernickeKorsakoff syndrome. Philadelphia: F. A. Davis.

von Cramon, D. Y., Hebel, N., \& Schuri, U. (1985). A contribution to the anatomical basis of thalamic amnesia. Brain, 108, 993-1008.

WichmanN, T., \& DeLong, M. R. (1996). Functional and pathophysiological models of the basal ganglia. Current Opinion in Neurobiology, 6, 751-758.

Young, H. L., Stevens, A. A., Converse, E. K., \& Mair, R. G. (1996) A comparison of temporal decay in place memory tasks in rats with lesions of thalamus, frontal cortex, and the hippocampal system. Behavioral Neuroscience, 110, 1244-1260.

Zhang, Y. P., Burk, J. A., Glode, B. M., \& Mair, R. G. (1998). The effects of thalamic and olfactory cortical lesions on continuous olfactory DNMTS and olfactory discrimination in the rat. Behavioral Neuroscience, 112, 39-53.

(Manuscript received July 28, 1998; revision accepted for publication February 10, 1999.) 